\title{
Studies on Utilization of Low Cost GSM-Bluetooth Based Home Automation System
}

\author{
S. Naga Mallikraj ${ }^{1}$, N. Thirupathi Rao ${ }^{1}$, Ch. Sekhar ${ }^{1}$, \\ Debnath Bhattacharyya ${ }^{1}$ and Tai-hoon $\mathrm{Kim}^{2 *}$ \\ ${ }^{1}$ Department of CSE, Vignan's Institute of Information Technology (A), \\ Visakhapatnam, AP-530 049, India \\ ${ }^{2}$ Department of Convergence Security, Sungshin Women's University, 249-1, \\ Dongseon-dong 3-ga, Seoul 136-742, South Korea \\ \{mallikblue,nakkathiru, sekhar1203, debnathb\}@gmail.com \\ *taihoonn@daum.net
}

\begin{abstract}
Presently the fast improvement of advances in technology makes things done as such effectively. The current article primarily concentrates on controlling home machines remotely with a solitary press on android telephone in which the created application is introduced and giving security when the client isn't in the place. This structure has fundamental features made with the objective out of slightest power usage for controlling lights, fans and distinctive equipment could be proscribed by methods for sending the SMS message using a GSM module from wherever having a framework hail. A Bluetooth component is in like manner interfaced with microcontroller. This Bluetooth component wipes out the utility blames by granting for the mechanical assemblies through Bluetooth when the android application is in a confined extent of few meters. In case the customer isn't using android phone, DTMF is in like manner interfaced so that by calling and crushing a foreordained keys can control the machines. The structure instructs customer about any peculiar conditions like intrusion disclosure, carbon-monoxide and temperature ascend by methods for SMS from the GSM module or by Bluetooth module to the customer's adaptable and moves are made as requirements be by the customer.
\end{abstract}

Keywords: Bluetooth, GSM, Home Automation, DTMF, LCD

\section{Introduction}

The GSM-Bluetooth based Home Automation System intends to design and execute a handy game plan that will give controlling of home machines remotely and will in like manner engage home security against interlopers without property holder. The motivation is to urge the customers to mechanize their homes having all inclusive access. The structure gives availability in light of change of an insignificant exertion system. The home machines control structure with a sensible cost was accepted to be developed that should be convenient giving remote access to the devices and allowing home security. Home security has been a critical issue where wrongdoing is growing and everybody needs to take genuine measures to balance intrusion. In addition there was a need to modernize home with the objective that customer can misuse the mechanical movement with the end goal that a man can control the contraptions from everywhere. The structure accepts a phenomenal part in helping elderly and injured and it is especially beneficial.

Received (August 19, 2017), Review Result (November 5, 2017), Accepted (November 14, 2017)

* Corresponding Author 


\subsection{Scope}

The GBHAS goes for outlining a model for controlling the home machines that can be controlled remotely by means of an application.. The system facilitated with different the structure can be used as a piece of home, little working environments to the colossal strip malls (can be used from home to work environments to control the electrical contraptions), for remote access of machines (the home/office devices can be controlled in GSM compose or can be gotten to by means of Bluetooth or as a choice can utilize DTMF) and for the advancement of innovation inviting condition (fuses the utilization of innovation and making home robotization).

\subsection{Objective}

The primary goal of GBHAS is to have the capacity to control the home apparatuses utilizing android application remotely with minimal effort, successfully and productively.

a. Controlling Home Appliances by means of Application: To build up an application that incorporates the highlights of squeezing catches on android bolster gadgets this is easy to use. Squeezing catches on the application can be utilized to control the switches of home apparatuses.

b. Constant Sensor Modules: PIR movement sensor, gas sensor, surveillance camera and temperature sensor reactions with discovery of ongoing outcomes.

c. Secure Connection amongst Application and Microcontroller: Use of validation to utilize application to control apparatuses over the microcontroller with the goal that unapproved ones can't access the application.

d. Extensible stage for future upgrade: The application is to be very extensible, with probability of including highlights later on as required.

e. Controlled by a cell phone in which we can discover in everybody's pocket: To make the home machines adaptable in charge, android devices (phone, Tablet) will ready to control the home apparatuses from remote area and as a choice any cell phone can likewise control machines by means of DTMF.

Proposed Users: The essential client of this framework is the person who has the android application introduced on his/her cell phone and approaches the application. Fundamentally relatives in home by just introducing the application on their android telephone they can screen and know the status of the apparatuses. In the event that the framework is introduced for office then colleagues can be the clients. Regardless the client must have the application introduced on his/her versatile and must login to the framework to access and control the apparatuses.

\subsection{Presumptions}

Certain presumptions must be made keeping in mind the end goal to actualize the task. The rundown of suspicions for this task are:

i. The client has individual phone(Android telephone by means of utilization and any telephone through calling)

ii. The SIM card which is in the GSM module gadget has dependably adjust to send SMS.

iii. There is dependably a system flag

iv. There is dependably control or the battery ought not be not as much as the expected add up to run the gadget. 


\subsection{Real Constraints}

Along the fulfillment of the venture I have experienced distinctive limitations and deterrents. It begins from the innovation. Since the implanted framework is another innovation, it is hard to get bolster from organizations. The other real imperative is getting the gadgets utilized for the framework. By requesting the gadgets online which is the main decision I have it requires investment in handling to convey and the things didn't accompanied datasheets along these lines finding and comprehension the datasheet is another issue. The gadgets unit without anyone else is another limitation. Since my experience is software engineering stream I got challenges with getting and understanding the gadgets and that is expensive, time taking and profoundly requires your understanding.

\section{Technological Consideration}

The three primary mechanical contemplations in this undertaking contain a decision of system, correspondence conventions and I/O interfaces.

a. Cell Networks: GSM which is generally accessible system gives wide zone scope and can be used more cost adequately for this venture.

b. Correspondence Protocols: the two correspondence conventions I utilized as a part of this undertaking are via SMS and Bluetooth and as an additional option phone calling.

c. Android Application: Now a day's most phones used are android phones which was used in this research paper we developed and android application so that the user can control the apparatuses effectively and knows the status of every machine.

\section{Examination of Existing Systems}

Every one of these frameworks is appropriate for checking relying on the prerequisites. PC based innovation is clarified. In this framework, PC is the remote observing position and microcontroller is the controlling device. Albeit one can screen and control gadgets distantly as of any piece of the world gave web get to be accessible, this framework brings about extra cost because of the necessity of a PC. Extraordinary equipment and programming establishment is required to control the gadgets. Likewise if there should arise an occurrence of energy disappointment, it is hard to screen and direct the position of gadgets unless you have a battery reinforcement which is an extra cost. Bluetooth based arrangements are additionally utilized for this reason. Despite the fact that Bluetooth dispenses with the utilization cost of the system, as it were, its scope of operation is restricted to a couple of meters. One can't remotely screen and control gadgets utilizing this innovation. Additionally it is attractive for each home gadget to have a committed Bluetooth module however because of the monetary cost of this sort of usage, a solitary module is shared by a few gadgets which have a weakness of access delay. Impedance is additionally an issue when utilizing this innovation. Likewise the remote frameworks can be gotten to utilizing any phone that backings double tone numerous recurrence. In this innovation all correspondence happens over a settled telephone and web isn't required. Be that as it may, clients are not furnished with a graphical UI, clients need to recollect get to codes and they need to retain which catch is to be squeezed to control which gadget. In addition it takes a lot of seconds to send guidelines so it isn't an exceptionally proficient innovation. 


\section{Proposed System}

The square chart of the research paper in which GSM-Bluetooth based framework is given in the following sections. In this framework both GSM and Bluetooth modules are interfaced with the fundamental controller chip and as an extra alternative DTMF is interfaced with the microcontroller. GSM is utilized for remotely checking and controlling the gadgets by means of a cell phone by sending and accepting SMS by means of GSM organize. Bluetooth is utilized for a similar reason however inside a scope of few meters, say when client is inside the outskirts of the building where the framework is introduced, Bluetooth can be utilized for speaking with the gadgets in this manner taking out the system use cost. This is an imperative value of the proposed framework. The home apparatuses are controlled by Bluetooth or GSM arrange through SMS. The framework advises client about any unusual conditions like interruption recognition, carbonmonoxide and temperature rise through SMS from the GSM module to the client's versatile and moves are made in like manner by the client. This prompts effective use of energy.

Definitions and Acronyms used in the research paper,

i. Appliance: A gadget or bit of gear intended to play out a particular undertaking.

ii. User: The one who has the application installed on his/her android mobile and who can log in to the application.

iii. Datasheet: Guideline manuals for electronic segments. They clarify precisely what a segment does and how to utilize it. The archives are normally composed by engineers for different architects, and all things considered they can frequently be hard to peruse, uniquely for new comers.

iv. Android: An open source operating system used to develop applications (Apps) for smart phones and tablets.

v. Piece Diagram: A graph appearing in schematic frame the general game plan of the parts or segments of the parts or components of a complex system or process.

vi. Circuit Diagram: An improved regular graphical portrayal of an electrical circuit. A pictorial circuit outline utilizes straightforward pictures of parts.

vii. Intruder: A person who intrudes, especially into a building or house with criminal intent.

viii. Hand-off: An electrical gadget, normally fusing an electromagnet, which is enacted by a present or flag in one circuit to open or close another circuit.

\section{System Overview}

Practical plan is a worldview used to rearrange the outline of equipment and programming gadgets. A practical plan guarantees that each measured piece of a gadget has just a single duty and plays out that obligation with the base of symptoms on different parts. The System intend Document describes the requirements of the proposed or to be developed system, architecture of the system and the subsystem, accepted formats for the input, layouts required for the processing of the output, interfacing of the humans with the machines, complete design, handing out login, and exterior interfaces. In the functional system design we will see the block diagram and the circuit diagram for the research paper. 


\subsection{Block Diagram}

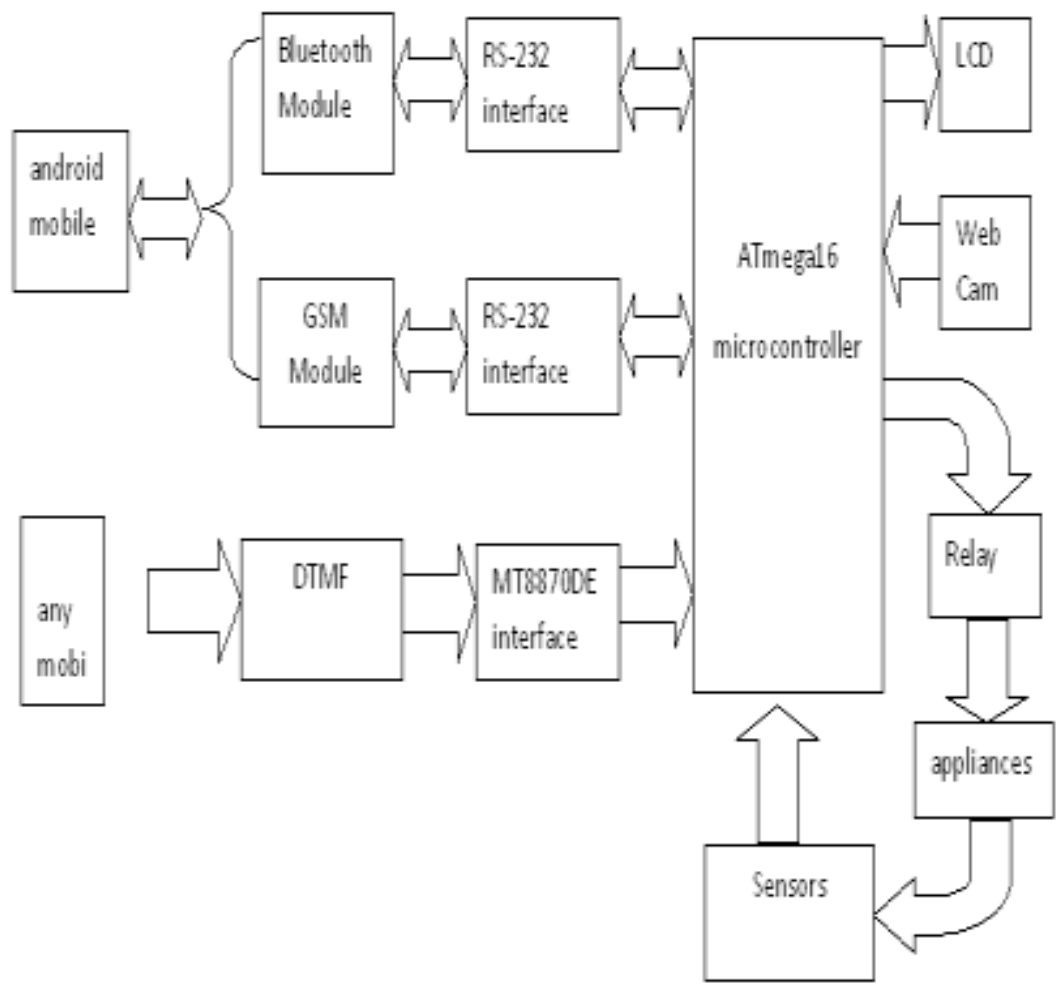

Figure 1. Block Diagram

\subsection{Description of Block Diagram}

The research paper is soldered by making the microcontroller at the centre. The sensors and communication devices are connected to the microcontroller.

i. Microcontroller: The brain of the current model which controls the overall activities. All devices are connected to it by using wires. The research paper uses Atmega16 microcontroller.

ii. Communication devices: They serve as a bridge between the microcontroller and the user. They are crucial for this research paper. Without the communication with the user, we can't say that the system is working.

a. GSM: sending and receiving of SMS between the user and the microcontroller.

b. HC-05 Bluetooth Module: to send and receive data between the microcontroller and Bluetooth support devices via Bluetooth.

c. LCD : to display the temperature

d. Relay: to control the home appliances as on and off

e. DTMF : to send frequency to the microcontroller via call

iii. Sensors: The research paper uses sensors to control the environment. The different sensors which are used in this research paper are:

a. Temperature: Used to get the current temperature of the environment 
b. PIR motion: To detect intruders when they got in to home by sensing the motion.

c. Gas : To sense the carbon-monoxide level of the environment which is dangerous and can lead us to death

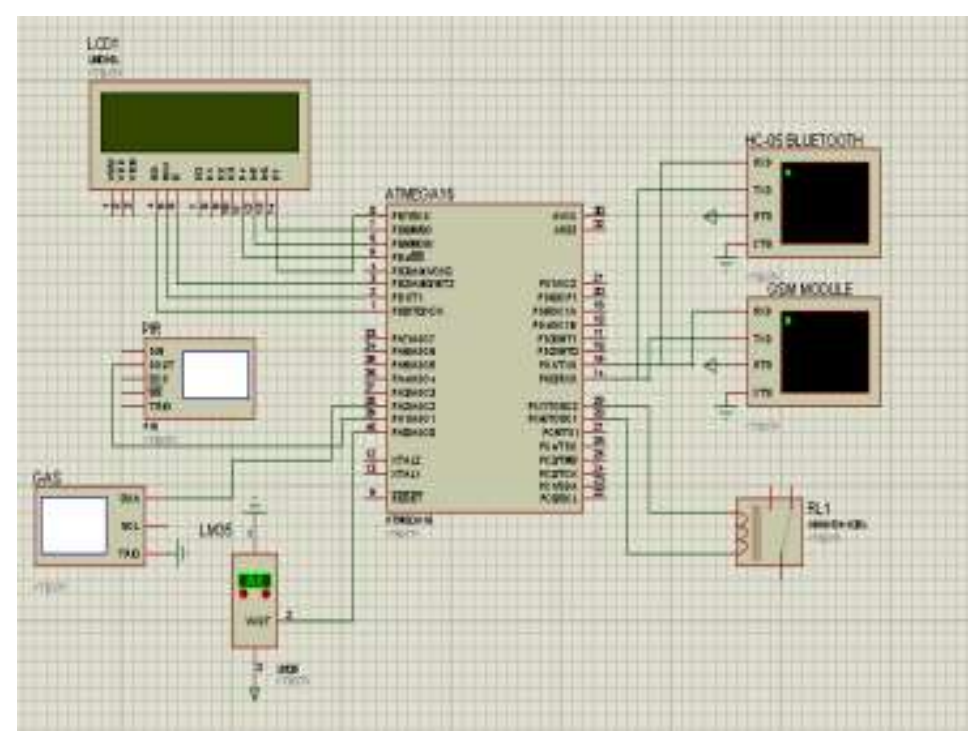

Figure 2. Circuit Diagram

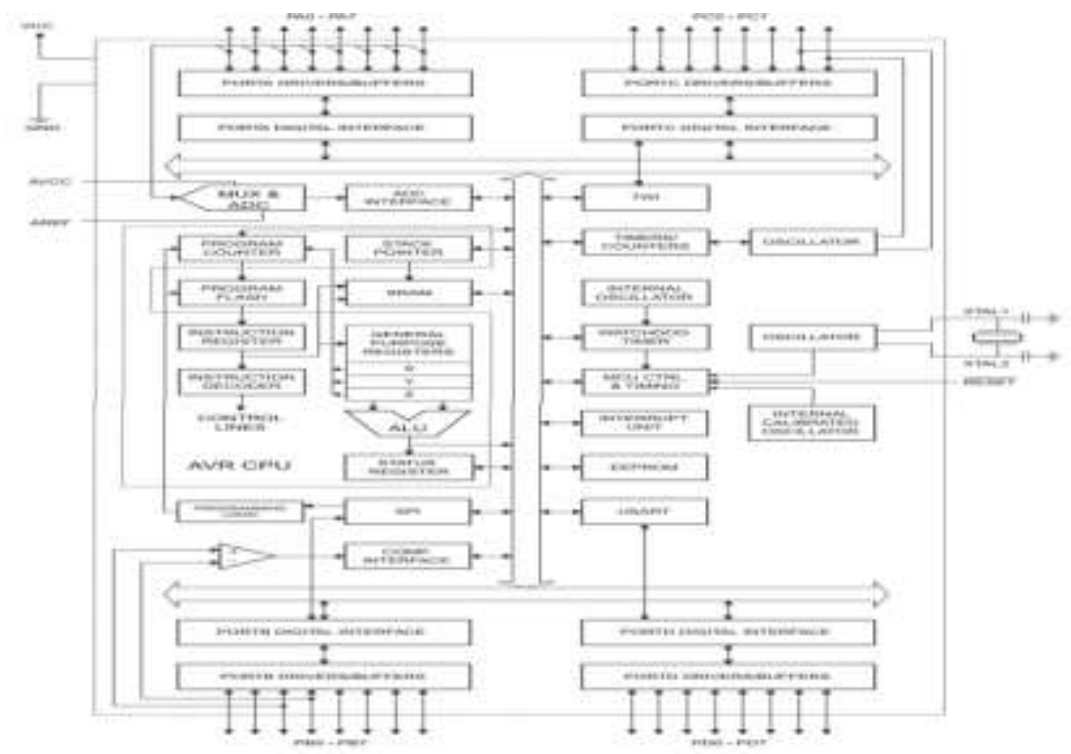

Figure 3. ATmega16 Block Diagram

\subsection{GSM Module}

GSM/GPRS modem-RS232 is worked with Dual Band GSM/GPRS motor SIM900A, chips away at frequencies $900 / 1800 \mathrm{MHz}$. The modem is accompanying RS232 chip (MAX232). The baud rate is arranged from 9600-115200 through AT summon. It is reasonable for SMS, Voice and also Data move application in M2M interface. Utilizing this modem, we can make sound calls, SMS, Read SMS, go to the approaching calls and web and so on through straightforward AT charges. Some of the commands used by the AT model are, 
Table 1. AT Commands

\begin{tabular}{|c|c|}
\hline AT Commands & Functions \\
\hline AT & checking working or not \\
\hline ATD+919030449160 & dialing to the number \\
\hline ATH & to hang the call \\
\hline $\mathrm{AT}+\mathrm{CMGF}=1$ & set format to text mode(SMS mode) \\
\hline $\mathrm{AT}+\mathrm{CMGL}=" \mathrm{ALL} "$ & to read all text messages \\
\hline $\mathrm{AT}+\mathrm{CMGD}=2$ & delete message at index 2 \\
\hline $\mathrm{AT}+\mathrm{IPR}=9600$ & set the baud rate \\
\hline $\mathrm{AT}+\mathrm{CLIP}=1$ & display the number of coming call \\
\hline $\begin{array}{l}\text { AT+CMGS }="+9190304491 * * " \\
>\text { Hello there }\end{array}$ & send "hello there" MSG to z number \\
\hline $\begin{array}{l}\text { AT+CREG? } \\
\text { +CREG: } 1,1\end{array}$ & $\begin{array}{l}\text { Returns the network status, first } 1 \text { is for } \\
\text { register and } 2 \text { nd one is GSM network }\end{array}$ \\
\hline $\begin{array}{l}\text { AT+CSQ } \\
+ \text { CSQ: } 17.0\end{array}$ & returns the signal quality of the network \\
\hline
\end{tabular}

\subsection{Software Design}

Embedded system is the harmonization of hardware and software to implement the need of the programmers. In this research paper, I use the following software's:
i. $\quad$ AVR studio 4
ii. App Inventor for Android Application
iii. Proteus 8 (Engineering simulation and designing tool)

\subsubsection{App Inventor for Android}

\subsubsection{Android}

It is an open source programming stage and working framework for cell phones in light of the Linux bit created by Google and later the Open Handset Alliance (OHA) which permits composing oversaw code in the java dialect. Android has its own particular virtual machine i.e DVM (Dalvik Virtual Machine), which is utilized for executing the android application. Features of Android

a. It is enhanced for cell phones

b. It empowers reuse and substitution of segments

c. Java bolster, media bolster, multi touch, video calling, multi entrusting, voice based highlights, screen catch, camera, Bluetooth, GPS, compass and accelerometer

\subsubsection{App Inventor 2}

Application Inventor 2 is the new form of App Inventor accessible at http://ai2.appinventor.mit.edu. It is awesome: it's considerably less demanding to setup (more often than no downloads!) and it gives a substantially more exquisite programming 
knowledge. The squares editorial manager stacks instantly (it's presently in the program, not a Java application!).

\subsubsection{Proteus 8 Demo}

\subsubsection{Introduction}

Proteus 8 Demo is the best reproduction programming for different outlines with microcontroller. It is for the most part well known in light of the accessibility of all microcontrollers in it. So it is a convenient device to test programs and installed outlines for gadgets specialist. You can reenact your circuit in Proteus Software you can straightforwardly influence PCB to plan with it so it could be across the board package. The one of a kind sort of schematic based microcontroller recreation with Proteus encourages quick, adaptable.

\subsubsection{ISIS}

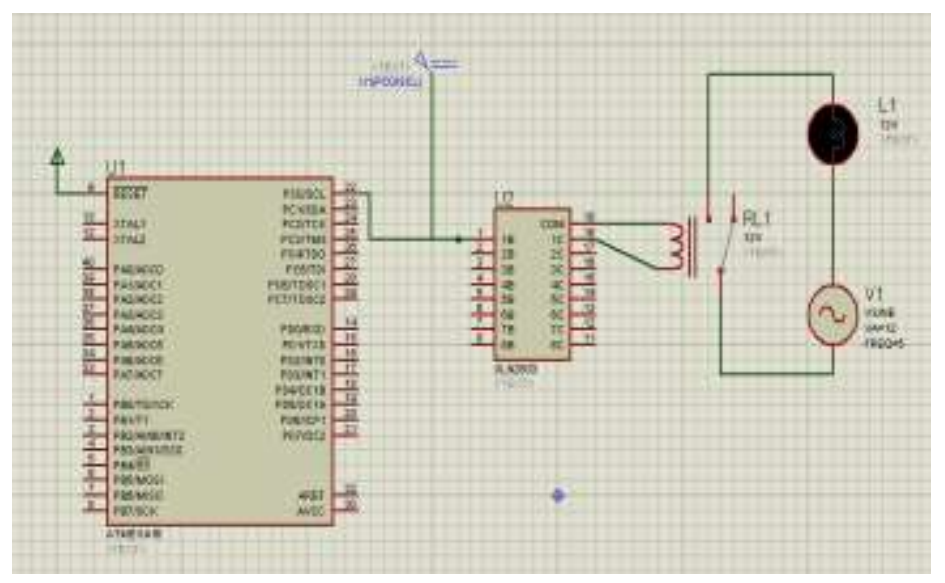

Figure 4. Sample ATmega16 Pins using ISIS

ISIS lies at the core of the Proteus framework, is significantly something beyond another schematics bundle. It joins an effective plan condition with the capacity to characterize most parts of the illustration appearance. Regardless of whether your necessity is the fast passage of complex plans for reproduction and PCB format, or the production of alluring schematics for distribution, ISIS is the apparatus for the activity.

\section{Results}

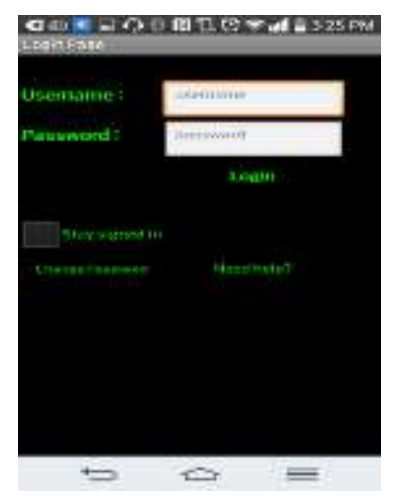

Figure 5. Login Screenshot 


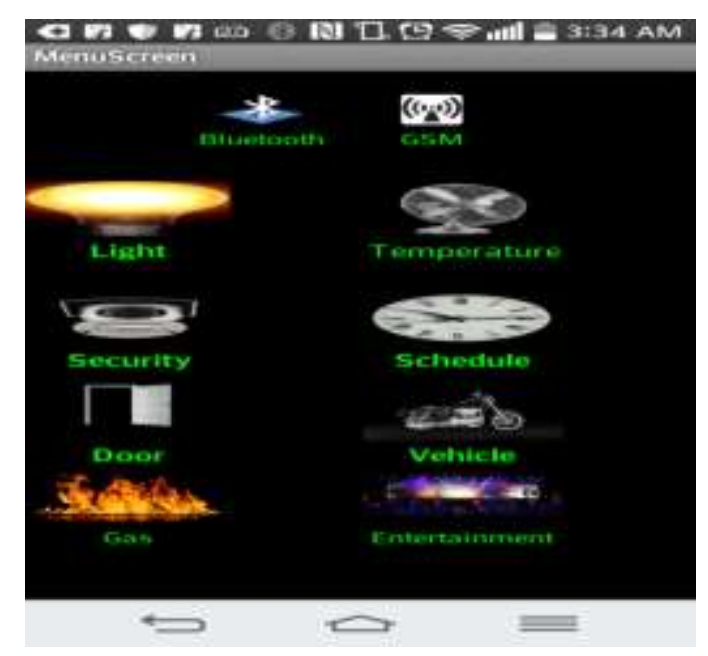

Figure 6. Menu Screenshot

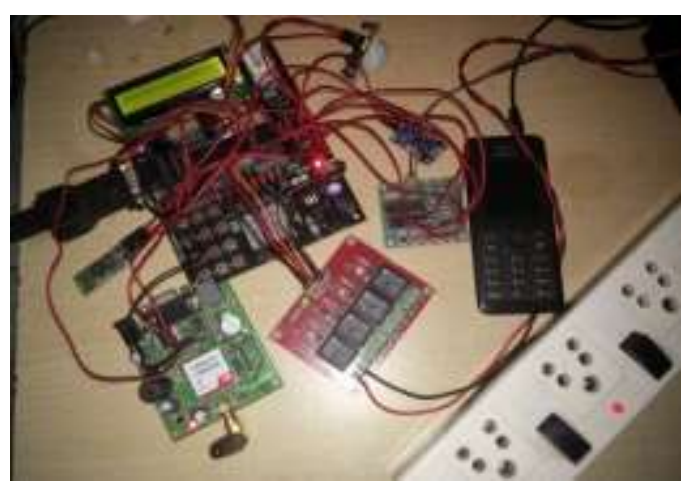

Figure 7. Microcontroller Connected with Different Devices

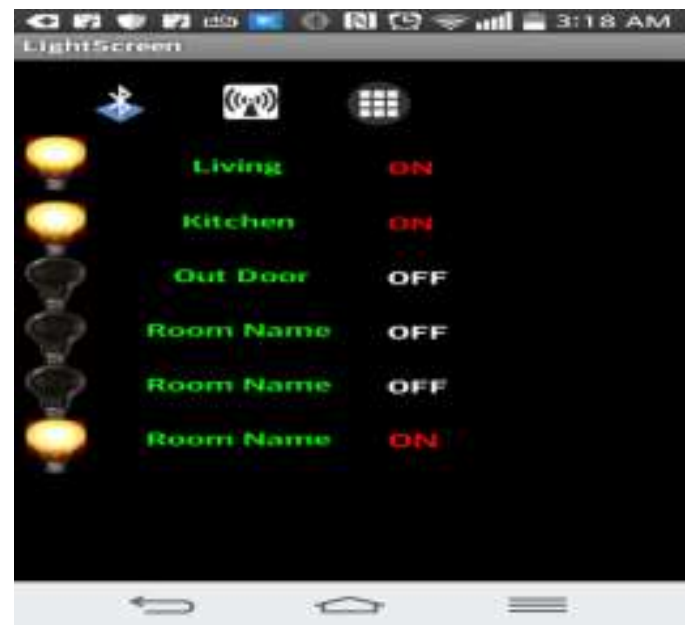

Figure 8. Light Control Screenshot

\section{Conclusion}

In the current article, the authors had presented a possible application of GSMBluetooth based home computerization framework which is minimal effort, secure, pervasively available and remotely controlled. In doing so I have tried to design an Android application which is very user friendly and the system also provides us options 
so while the user is in a limited range of area via Bluetooth and while the user is far away can use GSM and this all happens in a single touch in our android phone. DTMF is used as an option so that the user can use any mobile to control the appliances but with no interface. By controlling the lights, fans, heaters and other home appliances remotely we can save our money, energy and time. From this system we can also get flexibility, manageability and achieving security. For elderly and disables this system plays a great role.

\section{References}

[1] C. Felix and I. J. Raglend, "Home Automation Using GSM", Proceedings of 2011 International Conference on Signal Processing, Communication, Computing and Networking Technologies, (2011), pp. 15-19.

[2] K. Gill, S.-H. Yang, F. Yao, and X. Lu, "ZigBee-Based Home Automation System"; IEEE Transactions on Consumer Electronics, vol. 55, no. 2, (2009), pp. 422-430.

[3] N. Sriskanthan and T. Karand, "Bluetooth Based Home Automation System", Journal of Microprocessors and Microsystems, vol. 26, (2002), pp.281-289.

[4] C. Peijiang, J. Xuehua, "Design and Implementation of Remote Monitoring System Based on GSM", Pacific-Asia Workshop on Computational Intelligence and Industrial Application, (2008), pp. 678 -681.

[5] H. Huang, S. Xiao, X. Meng and Y. Xiong, "A Remote Home Security System Based on Wireless Sensor Network and GSM Technology", Second International Conference on Networks Security Wireless Communications and Trusted Computing, vol. 1, (2010), pp. 535-538. 